\title{
Dynamics of Social Capital among Resource Poor Rural Women
}

\author{
K.P. Raghuprasad*, N.R. Gangadharappa ${ }^{1}$ and U. Ravindra ${ }^{2}$ \\ Directorate of Extension \\ University of Agricultural Sciences \\ Bangalore, India
}

\begin{abstract}
Social capital is an important dimension for rural development which helps in transforming people into active citizens by adopting a bottom-up approach, influencing the ability of individuals and groups to cooperate in taking advantages of emerging opportunities. Social capital, if built among the resource poor women, can jointly take up economic activities to improve their livelihood. This study was carried out to explore the dynamics of social capital among the resource poor schedule caste and schedule tribe rural women through mushroom cultivation as an agro-based enterprise using locally available agricultural wastes. An Ex-post Facto Cause to Effect design was used to analyse the impact of social capital. The number of people with low social capital decreased from 31 to $20 \%$ and those in medium and high social capital categories increased from 45 to $47.5 \%$ and 24 to $32.5 \%$, respectively. These variables help the self help group members to expose to new situations and thereby facilitate them to attempt collective action. Correlation analysis revealed that all the domains of social capital were significant. The variables such as education, cosmopoliteness and mass media usage were significantly $(p<0.01)$ related with the social capital. The process aspects of building the social capital in the form of timely and suitable interventions have in fact yielded the results as expected. Constant encouragement for collective action, introduction of new remunerative enterprises and exposure activities would build social capital in rural areas and enhance trust on extension agencies to promote new ventures in rural areas.
\end{abstract}

Key words: Extension interventions, Social capital, Sustainable rural livelihood.

\section{INTRODUCTION}

Vulnerable individuals and communities often tend to be impoverished. Social capital is an important dimension for development which is shrinking in developing countries in recent years. Sound social capital would play a decisive role in creating sustainable livelihood among rural masses. Social capital building approaches are increasingly used in poverty alleviation programmes. As Pretty and Ward (2001) pointed out "the term captures the idea that social bonds and norms are important for sustainable livelihoods. Furthermore, the social capital is linked to people, their lives and their surroundings. However, social capital can also be defined as the resources available to one through the networks that they hold. Coleman (1988) described social capital as "The structure of relations between actors and among actors and that encourages productive activities". According to World Bank (1999) social capital refers to "The institutions, relationships, and norms that shape the quality and quantity of a society's social interactions. Social capital is not just the sum of the institutions

To whom correspondence should be addressed to: kpraghuprasad@yahoo.co.in

State JFPM Co-ordinator, UAS Bangalore, India

University of Agricultural Sciences, Bangalore, India 
that underpin a society-it is the glue that holds them together". Social capital not only helps to alleviate rural poverty but also helps in maintaining social and environmental balance, too. It influences the ability of small holding individuals to venture into new enterprises to broaden their livelihood options. Individuals and-groups who can work collaboratively and establish and maintain both trust-based relationships and networks of contacts will have more advantage (to take up remunerative agro based activities). The reason is that agroenterprises compete in complex supply chains that are technically demanding, information intensive and require coordination among different stakeholders at different stages of the process (Johnson et al., 2002). Hence, the positive effects of social capital in this direction are: Reduction of transaction costs; facilitation of the dissemination of knowledge and innovations, promotion of cooperative and/or socially - minded behaviour, benefits for individuals, social spill-over and less capital intensive interventions and people centred perspectives.

In this context, social capital enables the vulnerable and marginalised sections of the society to empower and bring them into the mainstream of development and builds a conducive climate for betterment of their livelihood. For this, it is desirable to promote suitable enterprises along with timely interventions to build the social capital. Mushroom cultivation using locally available agriculture waste was found the most appropriate enterprise for the resource-poor SC/ $\mathrm{ST}^{3}$ (Scheduled caste / Scheduled tribe) rural women.

With this background, the research study has been conceptualised to examine the dynamics of this social capital and its socio-economic profile of the respondents and their relationship to the dimensions of social capital and to assess the impact of extension interventions on social capital through mushroom cultivation.

\section{MATERIALS AND METHODS}

The study was carried out in 2007 in four districts of Karnataka state of India viz. Shimoga, Mandya, Hassan and Tumkur, where agricultural wastes like areca and coffee husk, sugarcane trash and coconut coir pith are available in abundant quantities, since these crops occupy sizable area in these districts. But, the wastes of these crops are not being used potentially by the farmers of these districts. This would provide an opportunity for the villagers, especially vulnerable sections to have additional income generating activity by growing mushroom using these wastes.

The villages for conducting this research were identified by considering the area of the crops mentioned above and quantity of the agricultural wastes available, population of SC/ST rural farm women and the existence of active women Self Help Groups (SHGs) in the villages. The present status of the agricultural wastes and the opportunities of using them for producing mushroom were ascertained by applying different Participatory Rural Appraisal (PRA) tools like transect walk, resource mapping exercises, wealth ranking exercises, resource flow diagrams, etc.

From among the selected districts four villages namely Honnaville, Bevinahalli, Kadlur and Basavapura were selected from the four identified districts for this study, since SC / ST population is found to be high and many SHGs from these communities are active in these

SC/ST: Scheduled caste / Scheduled tribe community which are considered as socially disadvantaged groups in the society. 
villages. Further, these villages are situated reasonably near the towns / district headquarters, which would facilitate easy marketing of the produce.

From each village selected for the study, one women interest group comprising of SC / ST population was formed from the existing SHGs. The group consisted of 20 members, as per the existing structure for formation of a self help group. The respondents were selected based on their interest and voluntary participation to take up mushroom cultivation on a sustained basis. Thus the total sample constituted 80 respondents at the rate of twenty members per group from each village. An interview schedule measuring the social capital of the rural women along with their profile was developed. The schedule was pre-tested on $10 \%$ of the sample and based on the results, the schedule was structured, sharpened and standardized. Statistical tools like paired t test and correlation were used for analysis of the sampled data.

\section{Measurement indices of social capital}

Social capital has been referred to as an empirically elusive concept by many. But, recent years have seen a surge in development of measurement indices for social capital with the Social Capital Assessment Tool (SOCAT) developed by the World Bank (2003 a) being the most widely recognized. Hence comprehensive scale was developed and standardized to measure the "Social Capital" comprising of 6 dimensions, namely "Empowerment and Political Action, Group Dynamics and Networks, Trust and Solidarity, Collective Action and Cooperation, Information and Communication, and Social Cohesion and Inclusion". The SOCAT of Word Bank was the base for developing a social capital scale to suit this research study. The data were collected twice-once before the extension interventions to build social capital among the target group during March to April 2006 and the other after the experiment during February to March 2007.

\section{Extension interventions}

During the period of study, series of extension interventions like personal visits, focused group meetings and training programmes (Table 1) were conducted based on the necessity in the four selected villages to build social capital among these respondents along with creating awareness and interest about the productive use of agricultural waste for mushroom cultivation and its advantages in terms of generation of income, employment, enhancing the food nutritive value and reduction of pollution.

Table 1. Extension interventions during the study period

\begin{tabular}{lc}
\hline Intervention & Number \\
\hline Orientation of all SHG members of the village & 04 \\
Focused group meetings & 04 \\
Skill training on mushroom cultivation & 08 \\
Capacity building activities on processing, value addition, marketing, & 04 \\
packing and storage of mushroom & 07 \\
Follow-up visits & 23 \\
Telephone calls & 01 \\
Technical bulletin (in Kannada) & \\
\hline
\end{tabular}




\section{RESULTS AND DISCUSSION}

\section{Socio-economic profile}

Twenty four variables were studied during the period of research including five situational variables. Of 80 respondents, majority was middle aged (62.5\%), one-third were illiterates $(32.5 \%), 80 \%$ were married, two-thirds lived in tiled house $(66.25 \%), 50 \%$ possessed cooking stove and majority of them $(81.25 \%)$ had less than one acre land holding.

Among them more then half of the respondents (55\%) were in the income range of Rs. 10002000/- (Indian) per month and 61.25\% had savings in the range of Rs.100-200 (Indian) every month. In general more than half of the respondents $(56.25 \%)$ had no participation in any kind of extension activities and medium level aspiration (50\%). Nearly half of the farm women had low cosmopoliteness (47.5\%) and medium level risk taking ability $(47.5 \%)$. Among the respondents, one-third had high trust in agency (35\%), three-fourths $(70 \%)$ had high economic motivation and half had medium level of mass media usage (52.5\%). Further $50 \%$ of the respondents live within $5 \mathrm{~km}$ distance from the nearest city, nearly half $(46.25 \%)$ had low level of innovativeness and more then half had low level of decision making ability $(60 \%)$.

With regard to situational variables, majority of them were unaware of government polices $(63.75 \%)$, did not have membership in any institutions (93.75\%), felt socially secured $(75 \%)$, customs and traditions allowed them to participate in social activities $(87.5 \%)$ and in two villages they felt that they were not much excluded from the society $(76.25 \%)$.

It implies that the respondents were belonging to low profile section of the rural community with low education, less land holding, minimum income and shouldering more family responsibility with minimum amenities. For them, timely extension intervention and suitable enterprises are very much necessary to improve their livelihoods.

\section{Overall social capital status of the respondents and its contributing factors}

The analysis presented in Table 2 shows that there was a significant impact on all the domains of the social capital due to the extension interventions carried out as part of the research study. On the whole, the overall social capital fell off from 31.25 to $20 \%$ under low group; whereas it saw a surge of 45 to $47.50 \%$ and 23.75 to $32.50 \%$ under medium and high categories, respectively. The overall mean score rose from 54.08 to 55.70 before-and-afterinterventions. All the domains of social capital were significant at $1 \%$ level of probability. It shows that the overall social capital status has improved significantly. The research findings of Sajeev (2006) and Gangadharappa et al. (2007) are in accordance with the findings of this study related to benchmark data. It implies that earlier these groups had minimal interaction, mutual help and co-operation, and less extension contact. These have been addressed properly through different interventions.

Extension interventions made a significant impact on social capital, since majority of the respondents $(65 \%)$ belonged to medium category in 'groups and networks' domain whereas, $56.25 \%$ of them came under high category after the extension intervention. The research findings of Sajeev (2006) and Gangadharappa et al. (2007) are in agreement with the findings of this study related to benchmark data. 
It implies that earlier groups were not working efficiently with very poor networking among themselves. Also, there was less contact with the external agencies and other groups which could be inferred from the earlier descriptions. These could be the likely factors for the respondents belonging to medium category. Due to the interventions, the outlook of the members has changed and hence, majority came under high category of social capital status.

Regarding the domain 'trust and solidarity', there had been a substantial increase under medium and high categories ( 41.25 to $47.50 \%$ and 36.25 to $40 \%$, respectively and decline in the percentage of respondents (22.50 to $12.50 \%$ ) coming under low category; Earlier, the respondents had trust only with certain agencies like Department of Women and Child Welfare and that too with few officials only. Appropriate interventions made the farm women to change their attitude and develop a positive outlook. Due to this effort, there had been an increase in medium and high categories. It is in conformity with the findings of Sajeev (2006) and Gangadharappa et al. (2007).

An upsurge of 5\% (35 to $40 \%)$ was observed in medium category under 'empowerment and political action' domain. Decrease from 47.50 to $43.75 \%$ of the respondents was noticed in low category, hence it is evident that the respondents are not much confident and had no influence in the family and SHG activities before the intervention. Because of extension interventions, they gained self-confidence, self-esteem and they attained a position to influence both their families and SHGs. Interestingly, it is in conflict with the finding of Sajeev (2006) and Gangadharappa et al. (2007) and related to benchmark data.

The same trend was observed under the 'collective action and cooperation' domain 37.50 to $48.75 \%$ under medium level and 10 to $30 \%$ under high level and 52.50 to $21.25 \%$ under low level. It could be inferred that there was very minimum group action earlier. After the interventions, the activities under this domain improved considerably and also collective action was noticed in other social developmental activities too. This finding is also in variance with the finding of Sajeev (2006) and Gangadharappa et al. (2007) and related to benchmark data.

Regarding the other two domains 'information and communication' (high from 18.75 to 21.25) and 'social cohesion and inclusion' (high from 27.50 to 32.50) and also the tendency of reduction in respondents under low and an improvement under medium and high categories were seen. After the interventions, the respondents had facility of access to more information sources than earlier and started using of advanced communication channels. The interventions could narrow the gap existing within and between the individuals and groups and there has been an improvement in the domain of social cohesion and inclusion. The research findings of Sajeev (2006) and Gangadharappa et al. (2007) are in accordance with the findings of this study and related to benchmark data.

This process can be related to the bonding and bridging concept of social capital given by Putnam (2000). Before starting the educational process on cultivating mushroom as an income generating activity, neither the bonding social capital nor the bridging social capital existed among the members of the SHGs, and hence majority belonged to the medium category before the initiation of interventions. The process aspects of building the social capital in the form of interventions have really yielded the results as expected. 
Table 2. Overall social capital status of the respondents

\begin{tabular}{|c|c|c|c|c|c|c|c|c|c|c|}
\hline \multirow{2}{*}{ Social capital domain } & \multirow{2}{*}{ Category } & \multicolumn{2}{|c|}{ Before intervention } & \multicolumn{2}{|c|}{ After intervention } & \multicolumn{2}{|c|}{ Before intervention } & \multicolumn{2}{|c|}{ After intervention } & \multirow{2}{*}{$\begin{array}{l}\text { Paired ' } t \text { ' } \\
\text { value }\end{array}$} \\
\hline & & No. & Per cent & No. & Per cent & Mean & SD & Mean & SD & \\
\hline \multirow{4}{*}{ Groups and networks } & Low & 10 & 12.50 & 04 & 5.00 & & & & & \\
\hline & Medium & 52 & 65.00 & 31 & 38.75 & 9.56 & 3.37 & 10.42 & 3.63 & $2.72 * *$ \\
\hline & High & 18 & 22.50 & 45 & 56.25 & & & & & \\
\hline & Low & 18 & 22.50 & 10 & 12.50 & & & & & \\
\hline \multirow[t]{2}{*}{ Trust and solidarity } & Medium & 33 & 41.25 & 38 & 47.50 & 13.38 & 5.26 & 14.16 & 5.38 & $3.55 * *$ \\
\hline & High & 29 & 36.25 & 32 & 40.00 & & & & & \\
\hline \multirow[t]{3}{*}{ Empowerment and action } & Low & 38 & 47.50 & 35 & 43.75 & & & & & \\
\hline & Medium & 28 & 35.00 & 32 & 40.00 & 6.78 & 3.32 & 7.25 & 3.58 & $3.78 * *$ \\
\hline & High & 14 & 17.50 & 13 & 16.25 & & & & & \\
\hline \multirow{3}{*}{$\begin{array}{l}\text { Collective action and } \\
\text { cooperation }\end{array}$} & Low & 42 & 52.50 & 17 & 21.25 & & & & & \\
\hline & Medium & 30 & 37.50 & 39 & 48.75 & 5.59 & 2.53 & 6.34 & 3.06 & $5.33 * *$ \\
\hline & High & 08 & 10.00 & 24 & 30.00 & & & & & \\
\hline \multirow{3}{*}{$\begin{array}{l}\text { Information and } \\
\text { communication }\end{array}$} & Low & 23 & 28.75 & 17 & 21.25 & & & & & \\
\hline & Medium & 42 & 52.50 & 46 & 57.50 & 11.06 & 4.09 & 12.06 & 4.50 & $5.11^{* *}$ \\
\hline & High & 15 & 18.75 & 17 & 21.25 & & & & & \\
\hline \multirow{3}{*}{$\begin{array}{l}\text { Social cohesion and } \\
\text { inclusion }\end{array}$} & Low & 19 & 23.75 & 11 & 13.75 & & & & & \\
\hline & Medium & 39 & 48.75 & 43 & 53.75 & 4.28 & 1.40 & 4.71 & 1.88 & $3.56^{* *}$ \\
\hline & High & 22 & 27.50 & 26 & 32.50 & & & & & \\
\hline \multirow{3}{*}{ Social capital } & Low & 25 & 31.25 & 16 & 20.00 & & & & & \\
\hline & Medium & 36 & 45.00 & 38 & 47.50 & 54.08 & 17.13 & 55.70 & 17.90 & $2.80 * *$ \\
\hline & High & 19 & 23.75 & 26 & 32.50 & & & & & \\
\hline
\end{tabular}

** Significant at $1 \%$ level 


\section{Relationship of the independent variables with overall social capital}

The correlation analysis revealed that level of education, cosmopoliteness and mass media usage were highly related with the social capital at $1 \%$ level of probability and the variables, monthly income, level of aspiration, economic motivation and decision making ability were significantly related with the social capital at $5 \%$ level of probability (Table 3 ).

The research findings of Sajeev (2006) and Gangadharappa et al. (2007) are in accordance with the findings of this study related to benchmark data.

The variables education, cosmopoliteness and mass media usage would help the SHG members to expose new things and situations, and finally facilitate the members to attempt with others, in taking up collective ventures. As a result, this promotes social capital among them. Further, the variables like monthly income, level of aspiration, economic motivation and decision making ability motivate the individuals to take up new ventures. During this course, they worked collectively and developed better social interactions among themselves.

It could be inferred from the above finding that the social capital status comprising six domains mentioned above could be considerably improved by manipulating the variables which have established significant relationship with social capital.

\section{CONCLUSION}

Apart from cultivating mushroom successfully, the intent of this study was to know social capital status of the vulnerable women and how extension efforts could build this domain to make them entrepreneurs. This would help the field functionaries to develop and design new initiatives to use the potentialities of women and bring them to the main stream of development. There was a significant impact on all the domains of the social capital due to the extension interventions carried out as part of the research study. Hence strategic measures have to be taken to design suitable extension interventions to improve the social capital status in rest of the villages, too. Further, they can target their efforts in building social capital among vulnerable groups in order to form a foundation for the promotion and adoption of new remunerative ventures to sustain their livelihoods. Frequent contacts by extension workers and other functionaries of development departments would certainly improve social capital status of the farm women. Constant encouragement for collective action, introduction of new remunerative enterprises and exposure visits would build social capital in rural areas and enhance trust on extension agencies.

The correlation analysis revealed that the variables education, cosmopoliteness and mass media usage were remarkably related with the social capital. Hence government has to give more importance to provide educational opportunities to these vulnerable sections of rural areas through either formal or non-formal means. Cosmopoliteness makes the farmwomen more aware of information and its utilization and causes to stay abreast with the latest innovations. Though information helps to set the stage for social capital developments, still majority of the women are not having access to mass media in rural areas. There are important implications of this study in terms of the importance of social capital accumulation among rural women and how this relates to their ability to adopt technology and ultimately participate in collective ventures. The set of intrinsic motivations resulting from these factors may expand rural women aspirations towards better situations and cause them set 
Table 3. Relationship of independent variables with overall social capital $(n=80)$

\begin{tabular}{lc}
\hline Variable & Correlation coefficient 'r' \\
\hline Age & 0.041 \\
Education & $0.467^{* *}$ \\
Marital status & 0.144 \\
Type of house & 0.171 \\
Material possession & 0.100 \\
Land holding & 0.096 \\
Monthly income & $0.218^{*}$ \\
Monthly savings & 0.169 \\
Extension participation & 0.066 \\
Level of aspiration & $0.224^{*}$ \\
Cosmopoliteness & $0.398^{* *}$ \\
Risk taking ability & 0.121 \\
Trust in agencies & 0.033 \\
Economic motivation & $0.229^{*}$ \\
Mass media usage & $0.412^{* *}$ \\
Distance from city & 0.070 \\
Innovativeness & 0.113 \\
Decision making ability & $0.251^{*}$ \\
\hline
\end{tabular}

* Significant at $5 \%$ level

** Significant at $1 \%$ level

more compelling targets. The results of the study suggest a need for further research to identify the other variables that help to explain social capital status. By understanding the dynamics in social capital development, initiatives have to be designed for better interventions. The strong social capital status being an accelerator of growth and development and also a platform for promotion of new technologies, assumes utmost importance for the popularization and promotion of alternative better technologies. This level of social capital does not hold the potential support and promote high-end application technology. Hence strategic measures have to be taken to improve the social capital status in all villages.

The results suggest a need for further research to identify other variables that help to explain social capital status. However, understanding some of the dynamics in social capital formation can help rural development leaders working in rural areas to design better interventions. The three variables that were identified as having a positive and significant contribution toward explaining social capital status are appropriate for utilization in this context.

\section{REFERENCES}

Coleman, J. S. (1988). Social capital in the creation of human capital. Am. J. of Sociol. 94, 95-120.

Gangadharappa, N.R., Acker, D.G., Chengappa, P.G., Ganesamoorthi S., Kumar S., Sajeev M.V. and Shen, D. (2007). Social capital and ability to change among Indian farmers. 
Johnson, N., Suarez, R. and Lundy, M. (2002). The important of social capital in Colombian rural agro-enterprises. Paper presented at the $25^{\text {th }}$ International Conference of Agricultural Economists, August 16-22, Durban, South Africa.

Pretty, J. and Ward, H. (2001). Social Capital and the Environment. World Development 29 (2), pp. 209-227.

Putnam, R.D. (2000). Bowling alone: The collapse and revival of American community. Simon and Schuster, New York, NY.

Sajeev, M.V. (2006). Scientists' perception and farmers' readiness towards GM crops. Ph.D. Thesis (Unpub). University of Agricultural Sciences, Bangalore, India.

The World Bank (1999). What is social capital? Poverty Net.

http://www.worldbank.org/poverty/ scapital/whatsc.html

The World Bank (2003 a). Social capital assessment Tool.

http://www.irisprojects.umd.edu/socat/ index.htm

The World Bank (2003 b). Reaching the rural poor: A renewed strategy for rural development (No. 26763): The Office of Publisher of World Bank, Washington DC. 